\title{
A PEDAGOGIA DA HEGEMONIA: EMPRESARIADO E A EDUCAÇÃO
}

\section{LA PEDAGOGÍA DE LA HEGEMONÍA: EMPRESARIADO Y EDUCACIÓN}

\section{THE PEDAGOGY OF HEGEMONY: ENTREPRENEURSHIP AND EDUCATION}

\author{
DOI: http://doi.org/10.9771/gmed.v13i2.43863
}

\begin{abstract}
Sara da Silva Freitas ${ }^{1}$
Resumo: O objetivo geral deste artigo é compreender a ação socialmente responsável do setor empresarial no Brasil. Buscou-se compreender como o setor privado desenvolve suas ações no campo das políticas sociais. Assim, como objeto específico de análise, temos as ações do Instituto Itaú Social, instituição vinculada ao Banco Itaú, à época desta pesquisa, o maior banco privado do país. Como método, utilizamos entrevistas semiestruturadas com dirigentes do Itaú Social, bem como pesquisamos os materiais disponíveis no site do Instituto. Como resultado, destacamos que a política educacional no Brasil se encontra em um dilema, estando, de um lado, os interesses do empresariado e sua tentativa de se sobrepor à sociedade e de se estabelecer hegemônico, e, de outro, aqueles que pregam uma educação como forma emancipadora.
\end{abstract}

Palavras-chave: Hegemonia. Educação. Empresariado. Itaú Social. Privatização.

Resumen: El objetivo general de este artículo es comprender la acción socialmente responsable del sector empresarial en Brasil. Buscamos comprender cómo el sector privado desarrolla sus acciones en el campo de las políticas sociales. Así, como objeto específico de análisis, tenemos las acciones del Instituto Itaú Social, institución vinculada al Banco Itaú, en el momento de esta investigación, el mayor banco privado del país. Como método, utilizamos entrevistas semiestructuradas con funcionarios del Itaú Social, así como la investigación de los materiales disponibles en el sitio web del Instituto. Como resultado, enfatizamos que la política educativa en Brasil se encuentra en un dilema, con, por un lado, los intereses de la comunidad empresarial y su intento de superponerse con la sociedad y establecerse hegemónica, y, por el otro, los que predican. una educación como forma emancipadora.

Palabras clave: Hegemonía. Educación. Emprendimiento. Itaú Social. Privatización.

Abstract: The general objective of this article is to understand the socially responsible action of the business sector in Brazil. We sought to understand how the private sector develops its actions in the field of social policies. Thus, as a specific object of analysis, we have the shares of Instituto Itaú Social, an institution linked to Banco Itaú, at the time of this research, the largest private bank in the country. As a method, we use semi-structured interviews with Itaú Social officers, as well as researching the materials available on the Institute's website. As a result, we highlight that the educational policy in Brazil is in a dilemma, being, on the one hand, the interests of the business community and its attempt to overlap with society and to establish itself hegemonic, and, on the other, those who preach an education as an emancipatory form.

Keywords: Hegemony. Education. Entrepreneurship. Itaú Social. Privatization.

\section{Introdução}

Este artigo é um desdobramento de uma pesquisa que teve como objetivo olhar para o campo empresarial no Brasil, por meio da chamada responsabilidade social empresarial, focalizando as ações do empresariado por meio de seus institutos e fundações. Como estudo de caso, escolhemos as ações do 
banco Itaú, à época desta pesquisa, o maior banco privado nacional. Além disso, o estudo de caso a partir do Itaú serve como modelo para pensarmos as ações do segmento empresarial no Brasil, visto que o banco Itaú é parte, como outras empresas, de um grupo de institutos e fundações, como o GIFE (Grupo de Institutos, Fundações e Empresas) e o Instituto Ethos, que compartilha dos mesmos projetos e ideias.

A pesquisa aqui apresentada traz dados do setor empresarial, em especial do Instituto Itaú Social. Assim, trazemos ao leitor um debate sobre a atuação do empresariado no campo das políticas sociais, com foco em política Educacional no Brasil, observamos que este material se trata de um extrato do que a parceria público-privado pode promover na educação brasileira.

O leitor encontrará elementos que podem ajudar a compreender o cenário atual de desmonte das políticas sociais, que tem como atores representantes do capital e do poder público envolvidos no discurso de responsabilidade social.

Neste artigo, expomos dados descritivos e analisamos entrevistas com membros da fundação Itaú Social, vinculada ao banco Itaú. Todas as instituições vinculadas a este banco foram procuradas, mas nos centraremos aqui nas ações do Itaú Social por ser a educação nosso foco de debate neste texto. Observamos que a escolha do banco Itaú e de seus institutos e fundações se deu porque, à época desta pesquisa, ele era o maior banco privado do país, bem como por sua atuação na área de educação e cultura, segmentos que têm um peso significativo nas ações da chamada responsabilidade social empresarial; desta forma, podemos vislumbrar a ação social dos empresários no Brasil. Outrossim, sabe-se sobre a atuação na área educacional do Banco Bradesco, outro gigante do setor financeiro nacional. Contudo, a atuação do Bradesco, por meio da Fundação Bradesco, não é nosso objeto de análise, e não se pretende fazer aqui um comparativo das fundações vinculadas aos bancos Bradesco e Itaú no que se refere à atuação destes frente à questão educacional; isso ficará a cargo de pesquisas futuras. A intenção é, por meio dos dados de um Banco, o maior do país, pensá-lo como modelo de atuação de uma fração de classe do empresariado brasileiro, qual seja, a do setor financeiro, no campo das políticas sociais, em especial da educação.

O objetivo é compreender de que forma o setor privado desenvolve suas ações no âmbito social e como este setor busca construir sua hegemonia por meio de uma pedagogia. Visto que, para Gramsci (1978; 1982; 2002), toda hegemonia é antes de tudo um processo pedagógico, compreendemos que, por meio dos trabalhos desenvolvidos pelos institutos e fundações vinculados às empresas (e, em nosso caso, aos bancos especificamente), opera-se uma construção pedagógica da hegemonia. Enfatizamos que nosso referencial para pensar o termo hegemonia é baseado na perspectiva marxista de Gramsci². Para este autor hegemonia é uma ação de classe, e significa o exercício do poder por um conjunto de indivíduos e uma classe determinada. É a maneira como o poder é exercido, não pelo do conjunto das instituições políticas, mas por meio da cultura. A hegemonia assim, se instaura por meio de agentes culturais, como os meios de comunicação, religião e pela escola.

Sobre a metodologia ela foi qualitativa e consistiu em análise documental (Relatórios das entidades pesquisadas, documentos produzidos como livros, cartilhas, notícias em jornais, dentre outros) e levantamento bibliográfico, que compreende trabalhos que se debruçaram sobre a questão da participação, 
sociedade civil e democracia no Brasil, que vão de meados dos anos 1990 até o ano de 2016, ano de conclusão de parte dessa pesquisa. Contudo, novas leituras foram incorporadas no texto, no sentido de atualizar o debate, vide Martins (2019) e Laval (2019). Além do estudo bibliográfico, foram realizadas entrevistas com dirigentes do Instituto Ethos, GIFE, Fundação Itaú Social e Instituto Itaú Cultural, todos com sede em São Paulo.

Foram realizadas 15 entrevistas com diferentes atores e grupos sociais; importante destacar que as entrevistas foram realizadas com gerentes, coordenadores de áreas da instituição, nesse sentido, as falas representam falas institucionais. Além destas, tivemos interlocução com aproximadamente 30 atores sociais que atuam no campo pesquisado, como funcionários dessas entidades.

\section{Empresariado e a Pedagogia da Hegemonia}

Constatamos, a partir dos anos 1990, uma mudança na agenda do empresariado nacional, que passa a se organizar em grupos autônomos e independentes, que, por sua vez, passam a constituir, no interior de sua classe, um debate sobre a questão social no Brasil.

Um dos grupos organizadores desse movimento empresarial foi o Pensamento Nacional de Bases Empresariais (PNBE), que participou do Movimento pela Ética na Política e organizou a campanha pelo impeachment do então presidente Collor em 1992. Em seguida, esse movimento se aproximou da Ação da Cidadania Contra a Fome, a Miséria e pela Vida, combatendo o problema social da fome. Todo esse movimento empresarial evidencia o empresariado como um sujeito importante na nova concepção do mundo social e político, e esta operação é realizada principalmente durante governo Fernando Henrique Cardoso, através do Programa Comunidade Solidária. O Instituto Ethos e GIFE, surgidos a posteriori, passam a ser os representantes dessa nova postura empresarial em relação às questões sociais. Outro instituto que desponta no meio empresarial é o Instituto Liberal, com atuação nas cidades do Rio de Janeiro, de São Paulo e do Rio Grande do Sul. Entretanto, ele está atrelado à difusão de uma ideologia da política liberal. Há também o IEDI (Instituto de Estudos para o Desenvolvimento Industrial), fundado em 1989, e que tem uma atuação diferente do Instituto Liberal. O objetivo do IEDI é representar a indústria e o conjunto específico de políticas ligadas ao setor industrial. Estes dois institutos, Instituto Liberal e IEDI, estão, portanto, na contramão do que propõem os demais institutos, PNBE, GIFE e Ethos, que se colocam como sendo mais um ator na sociedade civil.

Cabe ainda observar que, em 1996, o PNBE transformou-se em uma entidade de apoio a programas sociais, criando o Instituto de Desenvolvimento Social. Inicialmente, o foco principal era a empresa, tendo como missão disseminar uma nova consciência empresarial no ambiente corporativo e da sociedade, articulando empresários com a justificativa de tornar o país socialmente justo, economicamente mais desenvolvido e politicamente mais democrático. As ações da Fundação Abrinq e do GIFE tornam-se modelos. Essa mudança do PNBE abre várias brechas para uma nova configuração da realidade política brasileira. 
A ação socialmente responsável dos empresários ganha terreno simultaneamente à mudança do papel do Estado diante da questão social. No novo contexto de privatizações e desregulamentação público-estatal do mercado, surge um movimento chamado "Responsabilidade Social", que consiste na contrapartida dada por estratos da sociedade civil capitaneados pelo empresariado.

Em agosto de 2008, foi divulgado o resultado de uma pesquisa, realizada pelo IBGE (Instituto Brasileiro de Geografia e Estatística) em conjunto com o IPEA (Instituto de Pesquisas Econômicas Aplicadas), a ABONG (Associação Brasileira de ONGs) e o GIFE (Grupo de Institutos, Fundações e Empresas), que verificou a atuação de instituições sem fins lucrativos no Brasil. Com base no cadastro de empresas (CEMPRE) de 2005, a pesquisa apontou que existem, no país, 338 mil fundações e associações privadas e sem fins lucrativos (Fasfil). Em 2002, havia 275.895 entidades, sendo possível perceber um crescimento de 22,6\% no intervalo de tempo mencionado. Segundo o IBGE, tais resultados sinalizam uma “desaceleração" no crescimento do número dessas instituições, visto que de 1996 a 2006 o crescimento foi de 157\%. Em seu levantamento, o IBGE dividiu as associações de acordo com cinco características: por serem privadas; por não integrarem o aparelho do Estado; por não distribuírem lucros; por serem voluntárias; e por serem institucionalizadas.

O estudo aponta, em números absolutos, a existência de 83.775 entidades religiosas; já as de desenvolvimento e defesa de direitos chegavam a 60.259, o que representa, respectivamente, 24,8\% e 17,8\%. Os resultados demonstram uma forte ligação com a natureza confessional do associativismo brasileiro.

O IBGE classificou como ligadas à defesa dos direitos e aos interesses dos cidadãos aquelas entidades corporativas, patronais e de defesa de interesses de classe. Estas representam 17,38\% na pesquisa mencionada, sendo os dados, no entanto, analisados separadamente, com objetivo de se ter a real dimensão do que cada categoria representa no universo social.

Outro dado importante a ser observado nessa pesquisa é o baixíssimo número de entidades que trabalham com o meio ambiente e a proteção animal, apenas 2.562 entidades, o que não chega nem a 1\% do universo pesquisado. Em 2002, esses números eram ainda menores, apenas 1.591 entidades. Somente em 2005 essas instituições tiveram um crescimento expressivo de 38\%, contudo, vale ressaltar que entidades que trabalham com meio ambiente também podem estar diluídas no universo que aborda a questão da defesa dos direitos e interesses dos cidadãos.

Desse levantamento do IBGE, também merece destaque todo o discurso propagado pela mídia e assumido pela sociedade, principalmente quando o assunto aborda a questão da responsabilidade social.

O Estado capitalista neoliberal redefiniu sua arquitetura e suas dinâmicas, por meio da reforma do aparelho de Estado, com intenção de camuflar o Estado desenvolvimentista, produtor de bens e serviços, para um Estado gerencial responsável para a instauração de uma 'sociedade de bem-estar', no centro da qual aparecem as ideias de ONGs, terceiro setor e a responsabilidade social empresarial; aqui a sociedade civil é acionada. A burguesia, por meio do uso do Estado gerencial, sem abandonar o uso da coerção, passou a usar fortemente estratégias para a obtenção de consenso. E esse movimento é visto com 
a divulgação desses levantamentos do IBGE e do próprio (CEMPRE) Fasfil. É por meio dessas ações do empresariado no campo societal que podemos captar as estratégias e a dominação de classe da burguesia brasileira na atualidade (NEVES, 2011).

A Responsabilidade Social é um fenômeno que se instalou no Brasil e se intensificou a partir da década de 1990, obtendo força em instituições financeiras no país por ser esse setor fortemente estruturado, organizado por empresários nacionais e empresas multinacionais. Dentre os fatores influenciadores, destacam-se: a) a reorganização do capital, que muda o cenário econômico, tendo como pilar a competitividade mundial, regional e local e exigindo um perfil para a indústria e para os trabalhadores; b) aumento das condições de pobreza e da degradação ambiental, que culminou nos movimentos impactantes da ECO - Conferência das Nações Unidas sobre meio ambiente e desenvolvimento; c) a campanha contra a fome, de Herbert de Sousa(Betinho); d) as profundas transformações do mundo contemporâneo, provocando a incerteza e a instabilidade como fatores ameaçadores à sobrevivência das organizações empresariais, ao mesmo tempo que fortalece a valorização do conhecimento e do progresso orientados para o mercado; e) a insuficiência do papel do Estado, implicando nas graves críticas às políticas públicas marcadas pelo assistencialismo, pela insuficiência dos recursos e pela privatização dos serviços sociais; f) o crescimento da violência urbana; dentre outros.

Por meio de esforços do GIFE e do Instituto Ethos, foi possível difundir, no meio empresarial, o termo "responsabilidade social”. Através da campanha do IBASE (Instituto Brasileiro de análises sociais e econômicas) em 1997, com a publicação voluntária do balanço social empresarial, tendo como exemplo o guia da boa cidadania, propagou-se pelo país o discurso e as práticas da chamada responsabilidade social no meio empresarial. Um bom dado disso é o próprio crescimento do GIFE, que saltou de 26 entidades associadas em 1995 para 112 em 2008. Em 13 anos, a rede cresceu 208\% e, até maio de 2015, chegou a 125 entidades associadas. A Rede GIFE de Investimento Social Privado representa uma amostra qualificada do envolvimento das empresas com as áreas social, cultural e ambiental.

Segundo o Censo GIFE (2011-2012), os associados investiram cerca de R\$1,15 bilhão em projetos sociais, culturais e ambientais. Isso equivale a $20 \%$ do que o setor privado nacional destina à área social - cerca de $\mathrm{R} \$ 4,7$ bilhões, segundo dados do IPEA. A área priorizada pela rede para o investimento social privado é a educação, somando cerca de R\$ 124 milhões em 2005. Já no último Censo do GIFE (publicado em 2015), há um aumento de 18,44\% no volume total de investimentos, alcançando o valor de R \$ 3 bilhões investidos entre os anos de 2009 e 2014. Esse valor aproxima-se, por exemplo, do orçamento que o Ministério da Cultura movimentou em 2014, que foi de 3,27 bilhões (Lei n. 12.952/2014).

Já o Instituto Ethos, no ano de 2000, com apenas dois anos de existência, tinha 340 empresas associadas. Dados de 2021 indicam que o instituto conta com 444 associadas ${ }^{3}$. Em um primeiro momento, podemos dizer que tal tendência de responsabilidade social esteve ligada às grandes empresas, contudo, nos últimos anos, a ideia tem sido difundida entre empresas de menor porte, que antes alegavam falta de dinheiro ou de técnicas e conhecimentos sobre como agir. 
O que há de verdadeiramente inusitado, como destaca Santos (2005), é que, pela primeira vez, a crise da regulação social caminha pari passu com a crise da emancipação social. Segundo o autor, o projeto da modernidade, que repousa sobre os pilares da regulação expressos pelos princípios do Estado, do mercado e da comunidade, sobrepõe-se ao pilar da emancipação - marcado pelas racionalidades do direito moderno, da arte, da ciência e da técnica. Um fator que podemos ainda retirar do autor, que talvez nos ajude a pensar o porquê dessa sobreposição, repousa, portanto, em grande parte, no domínio do econômico sobre o social nos dias de hoje.

Nesse sentido, permanece atual e muito válido o campo de pesquisa apontado por Oliveira (2004). Ora, podemos afirmar que as empresas são um novo poder político no Brasil? Ou, ainda, como interrogaria Santos (2005), esse processo é parte de um novo modelo de regulação? Diria que se trata de um novo modelo de sociabilidade, uma sociabilidade construída por uma pedagogia da hegemonia (NEVES,2011), baseado em Gramsci (1978; 1982; 2002), já que, para este autor, toda hegemonia é uma ação pedagógica, e esta ação é difundida pelos agentes pedagógicos do empresariado, no caso, o GIFE e o Ethos, mas também por meio do discurso do terceiro setor de responsabilidade social, que ao final voltase para o capital. Tal processo causa uma transformação no campo da política social, já que o setor privado burguês passa a ter inserção significativa, ou seja, o foco das ações não é apenas o Estado, mas o conjunto das relações sociais, campo privilegiado da sociedade civil.

\section{Bancos e banqueiros}

A história dos bancos no país sempre esteve vinculada à questão do desenvolvimento econômico brasileiro. Observamos que esse direcionamento, no entanto, que os bancos dão à questão social, tem, em certa medida, um objetivo de melhorar a imagem e o tipo de relacionamento que essas instituições têm com a sociedade, ação iniciada nos anos 1970, mas fortalecida, com a tal responsabilidade social, a partir da década de 1990 (PEREIRA, 2007).

Como bem observou Minella (1988), os bancos atuam não somente no sistema financeiro, mas em toda cadeia produtiva: na indústria, no setor de construção civil, no setor de serviços, dentre outros, participando de uma rede infinita de ações no campo econômico e social. Segundo levantamento realizado em 20 instituições pela Federação Brasileira de Bancos (FEBRABAN), os investimentos, no ano de 2007, somaram $\mathrm{R} \$ 1.128,9$ bilhões, sendo, deste valor, $\mathrm{R} \$ 801,6$ milhões destinados a iniciativas sociais e $\mathrm{R} \$ 246$ milhões destinados a incentivos fiscais. A mesma Federação criou, em julho de 2002, uma comissão de responsabilidade social e sustentabilidade, que tem como missão disseminar as práticas de desenvolvimento sustentável no setor financeiro.

Um banco de relevante atuação social é o Bradesco. Segundo maior banco privado do Brasil, o Bradesco, que se intitula o banco do planeta, tem sua atuação na área social bem diversificada, indo da educação ao meio ambiente, passando pelas questões de cultura. Ele ainda faz parte do Índice de Carbono Eficiente (ICO2), desenvolvido pela BM\&F Bovespa e pelo Banco Nacional de Desenvolvimento 
Econômico e Social (BNDES), que tem como objetivo trabalhar com economia reduzida, de baixo carbono, além de adotar ações e políticas transparentes sobre as mudanças climáticas e a emissão de gases do efeito estufa. Para além dessas ações, vale destacar a Fundação Bradesco, que tem intensa atuação na área educacional em todo o país, fundada em 1956. No entanto, sua primeira escola foi inaugurada em Osasco, em 1962, com cerca de 300 alunos e sete professores. Os dados referentes a 2011 revelam que a fundação contava com 40 escolas e 112.081 alunos matriculados, atuando tanto no ensino fundamental quanto no ensino médio.

Contudo, não são só os bancos privados que têm atuação na área social, os bancos públicos também fazem parte desse conjunto de ação do setor financeiro no âmbito social. Exemplos mais evidentes disso são os programas da Caixa Econômica Federal e do Banco do Brasil, que atuam no campo da cultura e do esporte. O Banco do Brasil ainda conta com uma fundação, organização que tem atividades centradas no âmbito do desenvolvimento social, semelhante ao que fazem a Fundação Bradesco e a Fundação Itaú social. No entanto, como nosso objeto em questão são os grupos privados, não trataremos dos bancos públicos neste artigo.

O nosso foco em especial é o banco Itaú, maior banco privado nacional com forte atuação no campo educacional. Além de atuar no movimento todos pela educação, criou um instituto específico para a área de educação, no caso o Itaú Social. Nas próximas sessões trataremos da abordagem do banco e de suas ações.

\section{Itaú: o percurso do maior banco privado brasileiro}

O banco Itaú é um dos maiores bancos privados do país, fundando na cidade de São Paulo em 1943 como Banco Central de Crédito. É um banco voltado para o varejo, atua na área de seguros e crédito. Tem sedes em 20 países, como Argentina, Chile, Paraguai, Uruguai, Portugal, EUA, Japão e Inglaterra. No ano de 2006, fundiu-se ao Unibanco, um banco mineiro fundando em 1924. Com essa fusão, o Itaú ultrapassou seu maior rival, em termos de banco privado nacional, o Bradesco. O banco Itaú-Unibanco conta com aproximadamente 40 Milhões de clientes, 4 mil agências em todo o território nacional, 29 mil caixas eletrônicos e 35 mil pontos de atendimento no mundo.

Segundo levantamento de 2009-2010 realizado pelo GIFE, ${ }^{4}$ a educação continua sendo a área de maior investimento por parte do setor empresarial, em especial do banco Itaú, que tem o próprio presidente da Holding Itaú como presidente do Itaú Social.

Ainda segundo levantamento do GIFE, 59\% das suas entidades associadas ${ }^{5}$ atuam na área educacional, 24\% financiando ações educacionais. Isso corresponde a $83 \%$ das entidades do grupo envolvidas com a área educacional. Logo em seguida, aparece a cultura como a segunda principal área de investimento, $36 \%$ das associadas executam projetos e $24 \%$ financiam ações culturais, correspondendo ao total de $60 \%$ das entidades envolvidas com o setor cultural. O interessante a se observar é que, no ano de 2012, o GIFE lançou um dossiê especial sobre cultura. Os primeiros dossiês focaram a educação e a 
juventude e, em 2012, o foco direcionou-se para a cultura, dado a alta importância da área. Em 2013, a publicação se volta para o meio ambiente, que, apesar de contar com dossiê específico, é uma área que não recebe um grande volume de investimentos por parte das empresas associadas.

Existe no banco Itaú uma área denominada Sustentabilidade, e que faz parte de outra ação do banco que não está incluída na RSE, nosso campo de pesquisa. As ações de implementação das bicicletas no Rio de Janeiro e em São Paulo também fazem parte da Sustentabilidade, bem como aquelas ações de revitalização do centro antigo de São Paulo, em específico o Vale do Anhangabaú (PADILHA, 2015). ${ }^{6}$

Apesar de não ser o objeto em questão, é interessante observar e tentar perceber em que momento todas essas diversas ações devem ser olhadas separadamente e em que momento devem ser observadas conjuntamente. Explico: visto que no centro há uma intensa organização de movimentos sociais pró-moradia, e se há, como indicamos aqui, por outro segmento do banco, uma inclinação para o chamado campo dos direitos, não podemos perder de vista tais ações e a possível confluência desses setores, em específico no centro de São Paulo. Pelos levantamentos atuais, já há a exclusão da participação desses atores que vivem no centro do processo, contudo, são necessários mais estudos a respeito, o que ficará a cargo de outras pesquisas.

Desde a data da fusão do Itaú com o Unibanco, encontram-se, na área da Responsabilidade Social do banco, o Instituto Itaú Cultural e a Fundação Itaú Social, bem como os dois institutos oriundos do antigo Unibanco, o Instituto Unibanco e o Instituto Moreira Salles. O Instituto Moreira Salles, ${ }^{7}$ assim como o Itaú Cultural, tem seu foco voltado para a cultura. Já o Instituto Unibanco e a Fundação Itaú Social têm seu foco voltado para educação, ou seja, são entidades filiadas ao GIFE que investem maciçamente em educação e cultura.

Além dessas entidades, ainda há a Fundação Tide Setúbal, ${ }^{8}$ que não entra como RSE do banco, ainda que seja uma entidade vinculada à família que tem o controle do Itaú. Por isso, não se pode perder de vista as relações que marcam nossa sociedade, como essas relações vão se moldando, constituindo não só a esfera estatal, mas também a econômica, como bem demonstrou Lazzarini (2011) em seu Capitalismo de laços. Podemos ilustrar os laços do banco com a questão social da seguinte forma:

Figura I - Itaú e seus Institutos e Fundações

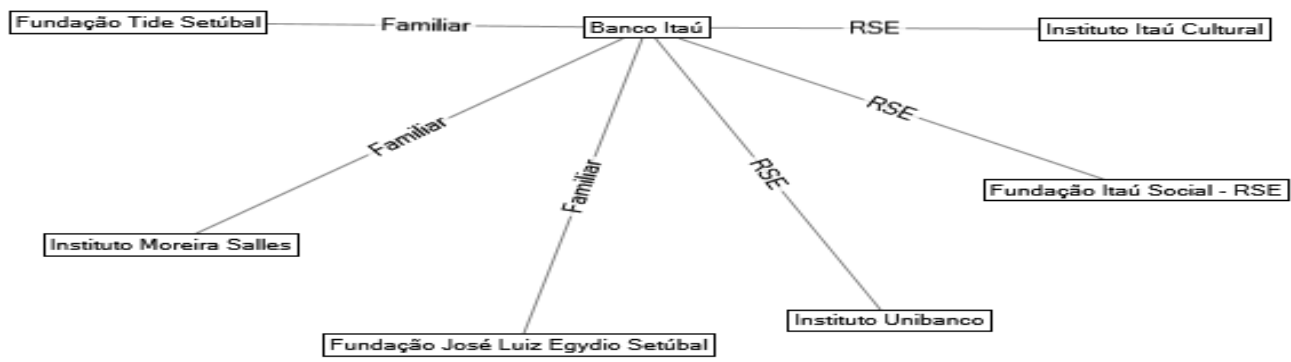

Created with NodeXL (http:J//nodexl.codeplex.com)

Figura 1. Fonte: Elaboração da autora. 
Em nossas visitas a campo, constatamos que o Itaú Cultural também desenvolve atividades em escolas. Segundo o próprio Itaú, tais atividades acontecem para uma melhor difusão e para o acesso à cultura de certos segmentos da sociedade, ou seja, a entidade também atua na área educacional. Isso talvez seja reflexo da ausência de contato entre as duas principais entidades do grupo Itaú: Itaú Cultural e Itaú Social. Durante o trabalho de campo, funcionários de ambas as organizações apontaram para a falta de diálogo entre as duas entidades: os encontros só acontecem em algum projeto específico ou em alguma atividade do Banco Itaú que envolva todas as organizações deste no campo da RSE. Fora isso, os contatos são mínimos ou quase inexistentes. Cada uma faz suas ações separadas e tem como núcleo a direção do banco, que coordena de forma separada cada uma dessas ações. Por isso, o diálogo entre as partes parece não existir, porque fica centrado só na direção do banco.

\section{Fundação Itaú Social}

Foi criada nos anos 2000 e vem atuando em todo o país em parceria com as três esferas de governo (municipal, estadual e federal), tendo como proposta de ação formular e disseminar metodologias voltadas a melhorias de políticas públicas no que concerne à área de educação e à avaliação de projetos sociais. Essa fundação conta com o apoio de diversos setores internos do banco Itaú, viabilizando os projetos sociais. Sua comissão executiva é presidida por Roberto Setúbal, pertencente à família fundadora do banco.

O banco Itaú criou um fundo patrimonial, composto por doações de empresas do Grupo Itaú, com recursos investidos em Fundos de Investimento (curto prazo e renda fixa) e em ações do Conglomerado Itaú. Em novembro de 2010, o patrimônio da Fundação Itaú Social (FIS) era de R\$ 528 milhões. O orçamento anual da fundação é resultante do superávit da aplicação nesse fundo. Em 2011, o valor destinado à aplicação nos programas da FIS foi de R\$ 78,5 milhões. Em dezembro de 2012, o valor desse fundo era composto por R\$ 3,4 bilhões, sendo usados nas políticas da instituição R 85 milhões. Para o ano de 2013, a previsão foi de um investimento na ordem de R\$90 milhões. Esse fundo é constituído por suas aplicações na bolsa, em ações. “Tem um pacote de ações, o rendimento desse fundo dá origem ao orçamento anual da Fundação. Então a gente está falando de R\$ 85 milhões em 2012 e tem uma previsão para 2013 de R\$ 90 milhões. [Estamos] vendo questões de aplicação, quanto que é o rendimento, mas é um fundo” (Coordenador do Itaú Social, entrevista realizada em junho de 2013).

Os gastos em 2013 ficaram, segundo o relatório anual de 2014, em R\$77,819, e, em 2014, em $\mathrm{R} \$ 82,690$ milhões. Outros dados apontam para o ano de 2015 um investimento aproximado de R\$ 105 milhões. Os últimos dados atualizados sobre os recursos investidos desse fundo em 2019 foram de R\$163 milhões - é o que consta no site da instituição "-, mas o levantamento que fizemos com pessoas que trabalham na fundação nos indicam que os números ainda estão sendo processados. De toda forma, são montantes consideráveis, visto que tais recursos são oriundos de fundos aplicados em bolsa, ou seja, diferente do Itaú Cultural, a Fundação Itaú Social, até o ponto em que pudemos verificar, não recebe 
nenhum tipo de incentivo fiscal.

É orientação do GIFE que seus associados façam um aporte patrimonial para manter seus trabalhos no campo do social, porque mesmo que a empresa feche, as ações no social continuariam. Vejamos o que significa efetivamente esse aporte. Se observamos os dados do próprio Itaú, o patrimônio saltou de R \$ 528 milhões em 2010 para R \$ 3,4 bilhões em 2013, um crescimento bastante considerável se analisarmos que o valor é resultante da aplicação no capital financeiro, que se baseia em lucros a partir de juros. Considerando que o juro seria uma cota da parte da mais-valia (MARX, 2011), então a burguesia nacional investe em ações sociais tendo como maior parte desses investimentos recursos que são oriundos, quando não de isenções fiscais, de aplicações financeiras.

O instituto possuía, à época desta pesquisa, 35 funcionários, todos vinculados ao banco, ou seja, não são funcionários do Itaú Social, mas sim do banco. Além disso, ele desenvolve seus projetos com base no fundo patrimonial,

Então é nessa base que os projetos são sustentados. Dentro da estrutura do banco, existe uma superintendência do Itaú Social, um funcionário do banco é responsável para executar o investimento social. E esse valor está no CNPJ da fundação, mas nós, como funcionários do banco, somos os responsáveis por executar [os projetos]. Então a gente, como área do banco, está ligado diretamente à presidência do banco. O Roberto Setúbal é o presidente do banco e é o presidente da Fundação Itaú Social, embaixo do Roberto tem um vice-presidente que é o [Antônio] Mathias, e embaixo dele tem a Valéria, que é a superintendente. E aí tem as equipes, tem a gerência de educação, as coordenações, tudo isso na estrutura. (Coordenador do Itaú Social, entrevista realizada em junho de 2013).

A fundação diz levar para as escolas envolvidas boas práticas de gestão e de planejamento, bem como as experiências e tecnologias desenvolvidas pelo banco. Isso ocorre em parceira com o governo, influenciando diretamente as políticas públicas. Ou seja, há um processo em construção que podermos denominar empresariamento das políticas públicas ou, como apontou Martins (2019), “empresariamento dos espaços de produção da política", no qual os espaços de participação e deliberação sobre as políticas públicas educativas, em muitos casos, são construídos e decididos pelo campo privado.

O Itaú, em especial, possui uma área denominada Sustentabilidade, que está na parte estrutural do banco e que pensa questões para além das sociais, segundo um dos nossos interlocutores do Itaú Social, essa área é pensada como um negócio, ou seja, os homens de negócios, transformam o social também em negócio. Aquilo descrito por Polanyi (2000), sobre o duplo movimento, em especial, o contramovimento, o de proteção social, parece encontrar no capital seu agente protetor, em se tratando de um "negócio do banco", precisa ser cuidado como tal. "É, pensando naquele conceito antigo, nem sei se é esse o conceito mesmo que estão usando, a área de sustentabilidade do banco está olhando muito as questões relacionadas ao negócio”. E esse “negócio” é legítimo e necessário dadas as responsabilidades que um banco tem frente a uma sociedade, e sendo este banco a maior instituição financeira privada do país.

Eu acho que o banco tem uma legitimidade para fazer isso mesmo, dado seu tamanho, como banco (o maior banco privado do país), e entendendo que ele tem responsabilidade no desenvolvimento dessa sociedade. Quando eu falo na área de 
sustentabilidade, aí sim eu estou olhando como que eu faço meus negócios de forma sustentável (Coordenador do Itaú Social, entrevista realizada em junho de 2013).

O banco Itaú, em um dos seus últimos relatórios, afirma que, para além de promover a educação básica, é importante estimular o pensamento crítico para a formação de cidadãos conscientes do seu papel, e, segundo a instituição, isso é realizado através dos investimentos em cultura.

Em 2011, os investimentos sociais e culturais alcançaram R $\$ 293,8$ milhões, com destaque para cultura e educação, que concentraram R \$184,2 milhões das receitas. No mesmo ano, houve um investimento de $\mathrm{R} \$ 54,8$ milhões em 66 projetos por meio da Lei Rouanet em oito Estados. Ainda por meio de leis de incentivo, agora na área de esportes, foram investidos $\mathrm{R} \$ 12$ milhões em 13 projetos relacionados ao esporte de alto rendimento, ao esporte educacional e a participações em atividades de lazer realizadas em 12 estados brasileiros.

A fundação Itaú Social, à época desta pesquisa, possuía quatro grandes áreas de atuação - gestão educacional, educação integral, leitura e escrita e avaliação de projetos. São os quatros grandes eixos para os quais se direcionam os recursos para desenvolvimento dos projetos.

Segundo um dos nossos entrevistados no Itaú Social, em 2011, a Fundação Itaú Social foi a única instituição brasileira convidada para participar da feira de inovação do encontro anual do Conselho Econômico e Social da ONU, evento que reuniu 600 participantes de todo o mundo e teve como tema a educação.

Além de ter um conselho de especialistas em educação e de acompanhar as pesquisas sobre o assunto, o banco, juntamente com a Fundação, possui uma lista de notáveis que opinam sobre os programas: observa-se, contudo, na fala abaixo, que entre esses notáveis, encontra-se representantes da burguesia nacional;

\begin{abstract}
Dentro dessa governança, a gente tem outro conselho, que a gente chama de grupo orientador. Ele não tem um papel deliberativo, não tem poder pra definir qual valor vai ser investido, onde vai ser investido, nada disso, mas ele é um grupo de orientação composto por pessoas do terceiro setor de outras organizações. Acho que é um super acerto porque ele acaba dando algumas diretrizes no rumo do trabalho. A gente tem nesse grupo a Viviane Senna, a Renata da Camargo Corrêa, o Gilberto Dimenstein (da Folha de São Paulo), o José Roberto Marinho (da Globo). É um conselho de pessoas que não estão aqui [mas no entanto] a gente apresenta nossas ações e eles palpitam. E a gente lógico que tem autonomia para definir se vai por esse caminho ou não. Mas são pessoas que a gente ouve para poder também dar uma diretriz para o trabalho. (Coordenador do Itaú Social, entrevista realizada em junho de 2013).
\end{abstract}

Outra ação do Itaú Social é o chamado Itaú Criança, criada com o objetivo de mobilizar a sociedade para a garantia dos direitos da criança e do adolescente. Dentre suas ações, está a divulgação do Estatuto da Criança e do Adolescente (ECA), uma tentativa de sensibilizar setores públicos sobre a aplicabilidade da lei. Em 2011, o programa realizou uma campanha nacional incentivando a leitura, na qual adultos leriam para crianças de até 5 anos. Os pais, educadores e voluntários que aderiram à campanha tiveram acesso gratuito à coleção de livros infantis do Itaú, tendo o banco disponibilizado três milhões de livros. Outra ação relevante foi desenvolvida em 4 mil bibliotecas de escolas públicas ou de organizações sociais indicadas por funcionários do Itaú: cada uma destas recebeu cem títulos para incrementar o acervo. 
O projeto ainda inclui a atuação da instituição em 31 Conselhos Municipais dos Direitos da Criança e do Adolescente - CMDCA.

\section{Sobre a educação integral10}

Uma das grandes áreas de atuação dos empresários e do Itaú está centrada na melhoria da educação, ou melhor, naquilo que esse setor vem fortemente fomentando, a chamada Educação Integral.

A educação integral proposta pela fundação tem como carro chefe dois grandes projetos: um é o prêmio Unicef e o outro é o Jovens Urbanos, que atuam em parcerias com secretarias de educação em todo o país, colaborando na estruturação de políticas de educação integral e na formação de professores que atuam em sua implementação.

O Prêmio Unicef, iniciado em 1995, tem como objetivo mobilizar, inovar, induzir e dar visibilidade ao trabalho das organizações sem fins lucrativos da sociedade civil. Alguns reflexos do ItaúUnicef em relação à educação integral são o programa Mais Educação, do Ministério da Educação, e a Escola Integrada de Belo Horizonte, parceria existente desde 2004. Em Goiás, além do apoio técnico e da formação de 400 gestores das 120 Escolas de Tempo Integral da rede estadual, a fundação participou também da reestruturação curricular. Este mesmo processo aconteceu em 91 escolas da rede municipal no Rio de Janeiro. No ano de 2011, a 9 a edição do prêmio recebeu 2.922 projetos inscritos, sendo os projetos separados por macrorregiões com sede nas cidades de São Paulo, Belo Horizonte, Ribeirão Preto, Goiânia, Belém, Curitiba e Fortaleza. Como prêmio, foi dado a cada um dos vencedores regionais (32 ao total) 20 mil reais.

O Programa Jovens Urbanos ${ }^{11}$ é voltado para jovens na faixa etária de 15 a 21 anos e seu objetivo é ampliar o repertório sociocultural dos jovens em situação de vulnerabilidade de maneira a contribuir para a transformação pessoal e coletiva. Uma das ações é o acesso dos jovens aos equipamentos e bens culturais e sociais das cidades. Em 2011, o programa ampliou sua atuação para a cidade mineira de Pouso Alegre, contemplando 500 jovens do ensino médio de escolas públicas.

E a educação integral está olhando a formação integral do indivíduo, da criança e do adolescente. Eu estou falando nesse conceito muito além do que a gente ouve por aí, e nisso a gente é pioneiro. Por exemplo, é um programa que a gente faz lá com o prêmio da UNICEF desde 1993 [...] tem um programa dentro dessa área, que é o Jovens Urbanos. Ele trabalha nessa área da periferia dos grandes centros e [a ideia] é pegar o jovem e fazer com que ele circule pela cidade, entre outras coisas de formação, para que realmente [amplie] o repertório cultural dele. Porque a gente sabe que tem casos como de famílias do Capão Redondo, onde estamos. São periferias que às vezes o moleque nasce lá, estuda numa escola do bairro, cresce, começa a trabalhar, vai trabalhar na farmácia da esquina, ele conhece uma menina que trabalha na padaria, casa, mora ali, tem filhos e esse ciclo é muito difícil de ser rompido, né. (Coordenador do Itaú Social, entrevista realizada em junho de 2013).

Para a Fundação Itaú Social, quando se fala em educação, devemos entender sua atuação junto ao sistema de educação pública, toda a atividade, as ações que o Itaú Social desenvolve, tem como foco a escola pública. Há uma parceria com o Ministério da Educação, em um projeto que funciona em ciclo de 
dois anos, relativo à formação de professores, visto que, por meio de tal parceria, consegue-se dar maior capilaridade ao projeto. Eles conseguem atingir 99\% dos municípios, ou seja, quase sete milhões de alunos.

A única pesquisa recente e relevante em âmbito federal realizada sobre educação integral no país é de 2009 (MEC, 2009), solicitada pela SECAD/MEC e realizada por um conjunto de universidades Federais (Unirio, UFPR, UFMG, UNB). A intenção foi mapear as ações realizadas sob o nome de educação integral no ensino fundamental. Com base nessa pesquisa e no Censo Escolar realizado em 2014, podemos extrair alguns dados importantes e que nos serão úteis para a análise do setor privado na área. Vejamos o gráfico a seguir:

Gráfico 1 - Parceiros da educação integral por região geográfica, 2008.

\begin{tabular}{|c|c|c|c|c|c|c|c|}
\hline \multirow[b]{2}{*}{ Parceiros } & \multicolumn{5}{|c|}{ Regiấo } & \multirow[b]{2}{*}{$\begin{array}{l}\text { Registros } \\
\text { (Total) }\end{array}$} & \multirow[b]{2}{*}{$\begin{array}{c}\text { Experiências } \\
(\%)^{(1)}\end{array}$} \\
\hline & Norte & Nordeste & $\begin{array}{c}\text { Centro- } \\
\text { Oeste }\end{array}$ & Sudeste & Sul & & \\
\hline Órgầos públicos & 5 & 88 & 13 & 101 & 46 & 253 & 31,6 \\
\hline Comunidade & 3 & 22 & 12 & 48 & 23 & 108 & 13,5 \\
\hline Empresas privadas & 2 & 13 & 7 & 37 & 24 & 83 & 10,4 \\
\hline ONGs & 2 & 22 & 2 & 28 & 6 & 60 & 7,5 \\
\hline $\begin{array}{l}\text { Instituições } \\
\text { comunitárias }\end{array}$ & 1 & 8 & 4 & 29 & 14 & 56 & 7.0 \\
\hline $\begin{array}{l}\text { Instituiçōes } \\
\text { religiosas }\end{array}$ & 2 & 11 & 3 & 25 & 12 & 53 & 6,6 \\
\hline Universidades & 3 & 14 & 3 & 21 & 9 & 50 & 6,2 \\
\hline Fundações & - & 8 & 2 & 17 & 14 & 41 & 5,1 \\
\hline Empresas públicas & 3 & 9 & 1 & 7 & 3 & 23 & 2,9 \\
\hline Outros parceiros & 2 & 16 & 2 & 20 & 8 & 48 & 6.0 \\
\hline Total & 23 & 211 & 49 & 333 & 159 & 775 & - \\
\hline
\end{tabular}

Extraído de: MEC, Secad, 2010. Base da amostra: 800 escolas. Fonte: Urbini, 2015

O importante a ser observado nesse gráfico é que se trata de escolas públicas e laicas, e o que visualizamos é um peso de entidades religiosas e privadas desenvolvendo atividades parceiras com as escolas, como é o caso do Itaú Social e de tantas outras fundações e institutos privados.

O projeto de escola integral é um dos projetos propagados e desenvolvidos pelo Itaú Social em formato de parcerias com vários municípios e estados brasileiros. Dois, no entanto, a nosso ver, merecem destaque: o estado de São Paulo e o estado de Goiás. No estado de São Paulo, o programa Escola em Tempo Integral começou em 2006 e, no ano de 2015, funcionava em 263 escolas, atendendo a cerca de 50 mil alunos do ensino fundamental. O programa funciona no contraturno das aulas regulares, com a ampliação das atividades esportivas e culturais. Além do programa Escolas em Tempo Integral, há ainda o denominado Novo Modelo de Escola em Tempo Integral (NMETI), que privilegia o ensino médio. Esse novo modelo começou a funcionar em 2012 e, em 2015, já funcionava em 257 escolas, atendendo a 80 mil alunos do ensino fundamental e médio (URBINI, 2015). 
A mediação do Programa NMETI é realizada por meio do OSCIP ICE-Brasil (Instituto de Corresponsabilidade em Educação), uma entidade privada que tem como prática testar o modelo de educação integral ao mesmo tempo que forma os jovens para o mercado de trabalho, por meio de seu plano pedagógico e do que o instituto chama de "Projeto de Vida". O ICE ainda se inspira no modelo de "escolas charter" e em suas tecnologias educativas, sendo um dos motes o compartilhamento da gestão escolar entre os setores públicos e privados. (DIAS e GUEDES, 2010, p.10, apud URBINI, 2015). Um de seus principais agentes financiadores é o Instituto Natura, conforme relato de uma professora: "Foi o Instituto Natura que financiou a implementação do programa entre agosto de 2011 a dezembro de 2012 [...]. As visitas que presenciei na escola eram de "parceiros" que se identificavam como membros vinculados ao Itaú-Unibanco” (URBINI, 2015, p. 215).

Nas escolas, em específico, tal mudança acontece de forma sutil e sempre com o discurso de que se trata de uma escola modelo. O formato de escola charter foi inicialmente implementado no estado de Pernambuco, no qual 160 escolas do ensino médio passaram a oferecer ensino integral. O mesmo modelo também foi implementado em Sergipe (3 escolas), no Ceará (60 escolas) e no Piauí (23 escolas), até chegar nos estados de São Paulo e Rio de Janeiro ${ }^{12}$ (URBINI, 2015). Essas escolas têm na parceria público x privado sua fonte de financiamento. Mas por se tratar de escolas charter, elas operam livres de muitas leis e regulamentações a que está submetida a maioria das escolas públicas. O que cabe destacar nesse modelo é que, embora sendo um número pequeno, as escolas charter ocupam um papel importante nas reformas educacionais que, apesar de públicas, têm sido geridas pelo campo privado, o qual influencia no debate das reformas educacionais para o sistema público, de forma geral,

A expectativa dos defensores do modelo é que ele provoque um efeito cascata, com repercussões nas decisões de gestão da rede pública da qual faz parte. Existem variações entre os tipos de legislação que regulam o funcionamento de escolas charter, mas algumas características comuns podem ser apontadas: a) Todas recebem financiamento público baseado no número de estudantes e são Cogerenciadas por uma instituição do setor privado, geralmente sem fins lucrativos; b) possuem muito mais autonomia que as escolas públicas regulares em itens fundamentais da gestão do ensino, como seleção e retenção de gestores e professores; c) a admissão de alunos é feita ou por meio de sorteio ou por critérios geográficos. (DIAS e GUEDES, 2010, p. 10, apud URBINI, 2015, 217-218).

Esse modelo de escolas charter tinha como base os exemplos de educação de Nova York e Chicago, tendo o Itaú Social, inclusive, publicado um material exclusivo sobre a reforma do ensino vivenciada pelas cidades americanas. Em 2009, o Itaú Social, em conjunto com o Instituto Fernand Braudel, publicou a experiência do ICE em Pernambuco. No entanto, ao relatar a experiência, a fala dos representantes do Itaú Social não cita as famílias, a comunidade estudantil, os movimentos sociais que tenham como pauta a educação, como agentes de transformação envolvidos com a melhoria da educação e da qualidade nas escolas, o relato era voltado apenas para o poder público e para o próprio empresariado (URBINI, 2015).

Em 2011, o modelo ICE-Brasil foi escolhido para ser aplicado no estado de São Paulo. O governo já era parceiro do Itaú-Unibanco no desenvolvimento do programa Jovem de Futuro, que em 
2010 já contava com 41 escolas e, no ano seguinte, com 208 escolas participantes (URBINI, 2015, p. 223). Já em relação à implementação do NMETI em São Paulo, merece destaque o depoimento de uma docente à época da implementação:

Nessa reunião nos apresentaram um vídeo sobre a experiência de ensino integral do ICE em Pernambuco e convidaram a nossa escola para aderir ao Novo Modelo de Escola de Tempo Integral, que seria implantado de modelo experimental e progressivo na rede estadual de São Paulo. Ainda que se frisasse o caráter voluntário da adesão, o convite veio acompanhado de um alerta sobre a possibilidade de fechamento da escola em caso de recusa. Naquela reunião muitas perguntas feitas pelos professores não foram respondidas pelo grupo de superiores, que diziam ser a iniciativa ainda experimental, sendo necessário da parte dos professores dar "votos de confiança" para as medidas de transformação. Em matéria publicada alguns meses depois no portal eletrônico da Ação Educativa, havia a seguinte declaração de uma das superiores, Valéria Souza, coordenadora da Educação Compromisso de São Paulo: "Das 21 [escolas] consultadas em 2011, 16 aceitaram iniciar o ensino integral em 2012. 'Foram corajosas, porque não tinha nem lei na hora que eles toparam"”. Os supervisores imaginaram que chegar com uma apresentação de PowerPoint sobre as vantagens de se aderir ao programa, aliada a informações sobre aumento da remuneração fosse informação suficiente. Foi suficiente para a escola aderir, mas à custa de muita irregularidade e autoritarismo. Seis meses depois, em abril de 2012, os professores que não aderiram e que foram removidos ainda pediam explicações em relação aos seus cargos e destinos. Aos professores que não podiam ou não desejavam aderir ao modelo, como eu, nos foi dada a opção de remoção para o Ensino de Jovens e Adultos que funcionava no período noturno, e após um semestre de aulas, houve encerramento das turmas do noturno (apesar da existência de demanda), e a necessidade de nova remoção. Aos pais e alunos que também não desejavam ou não poderiam aderir ao novo modelo, caráter declaradamente excludente, posto que encurrala justamente os alunos e professores com mais dificuldade de permanência para um número cada vez mais reduzido de escolas, em localizações mais afastadas do que suas escolhas originais, uma vez que o modelo tem se expandido. (URBINI, 2015 p. 224-225).

A descrição da autora demostra a forma autoritária e vertical das alterações no sistema de ensino e como as partes mais interessadas e de fato envolvidas são sequer escutadas. Enquanto isso, os representantes empresariais aparecem como parceiros "bonzinhos":

[Os] empresários do Itaú-Unibanco frequentavam a escola e eram apresentados como "parceiros", mas em nenhum momento consegui obter na escola, na secretaria de educação ou no sindicato informações mais precisas sobre a legalidade e a função dos "parceiros" na nova configuração do trabalho. (URBINI, 2015, p. 225).

Além de São Paulo e outros estados no Nordeste que implementaram e vêm desenvolvendo com o Itaú essa parceria na educação integral, existe uma outra parceria antiga do Itaú Social, que é com o estado de Goiás:

É na área de educação integral onde estamos, e a gente está fazendo o plano de educação integral no estado de Goiás. A gente está muito ligado às equipes de campo, à equipe da secretaria, eu acho que a gente vai garantindo a perenidade da ação. Porque mesmo se trocar o governador, ele muda o secretário [mas] a equipe permanece, né? Aí você tem um legado e tem compromissos que estavam assumidos e que vão ser executados. (Coordenador do Itaú Social, entrevista realizada em junho de 2013).

Não dispomos de detalhes da reforma do ensino no estado de Goiás, mas a forte parceria existente entre o Itaú Social com o estado data pelo menos de 2010. Nesse sentido, supomos que o plano de reforma escolar em voga nesse estado vá na mesma direção do que vem acontecendo em São Paulo e nos estados em que já foi implementado esse modelo de educação integral com suporte de institutos e 
fundações empresariais. Temos como base para essa afirmação a declaração da secretária de educação de Goiás, à época da realização desta pesquisa, Raquel Teixeira, que afirma que a ideia é melhorar a gestão dos colégios e deixar os diretores concentrados em questões pedagógicas. "Eles [empresários] estudaram economia, administração de empresas. Entendem mais de administração do que nós, educadores" (FOLHA, 2015). Nesse sentido, a intenção é implementar modelo semelhante ao adotado na saúde, agora na educação. No caso de Goiás, a tentativa é de transformar as escolas em Organizações Sociais (OSs) privadas para atuar e gerenciar as escolas públicas.

Áreas como a da saúde têm utilizado mais amplamente a legislação que rege as OS nas parcerias público-privadas. Na educação, essa é uma iniciativa ainda pouco disseminada, em parte porque a Lei das Diretrizes Básicas da Educação (LDB), de 1996, estabelece que recursos públicos da educação só podem financiar escolas comunitárias, confessionais e filantrópicas em forma de bolsas de estudo, o que torna instável a regulamentação das escolas charter no Brasil. Seria importante que a discussão em torno da revisão da LDB pudesse contemplar de forma mais clara o que na prática já vem funcionando, criando maior segurança jurídica e institucional às iniciativas de parceria público-privada na educação. (DIAS e GUEDES, p. 21, apud URBINI, 2015, p. 218219).

O que acontece na educação, a nosso ver, tendo o setor empresarial à frente e com apoio, em certa medida, de governos locais, é um duplo movimento. Não como descrito por Polanyi (2000), um que descreve a tentativa do mercado em se autorregular e outro no qual a sociedade se defende criando mecanismos de proteção. O que se constata nesse duplo movimento, na educação em especial, é um que visa terceirizar os serviços na área de educação, não contratando mais professores, esta é a atual política adotada por vários estados e municípios no Brasil, o regime estabelecido para a ocupação de profissionais neste campo tem sido um regime de contratação temporária. O outro movimento é aquele que influencia a política por meio de lobby ou advocacy, na mudança, por exemplo, da lei da LDB, em que há intensa pressão do setor empresarial para alterações na lei com o intuito de permitir esse processo de desmanche. A pressão toma forma como movimento social, basta olhar, por exemplo, quem compõe o Todos pela educação, ${ }^{13}$ e quem são seus parceiros. Importante observar que há uma participação de outros movimentos sociais e entidades como institutos e fundações que também têm pessoas da elite nacional engajadas, e há um movimento por parte destas em direção à área que historicamente sempre lutou pela ampliação dos direitos, a do chamado campo democrático participativo. ${ }^{14}$

A construção pedagógica de uma hegemonia aqui é algo além de uma implementação de sua visão de mundo na área de educação e cultura. Ela inclui também a captura daqueles que poderiam ser fonte de resistência. Utilizando as análises de Gramsci sobre o processo educativo - já que a pedagogia de Gramsci (1978; 1982; 2002) está vinculada ao conceito de hegemonia do autor, e a escola representa, em certa medida, esse papel de reforço de uma construção hegemônica, como instrumento que forma os intelectuais de diversos níveis - a marca da escola está no fato de existir um tipo escolar para cada grupo social. "A marca social é dada pelo fato de que cada grupo social tem um tipo de escola próprio, destinado a perpetuar nesses grupos uma determinada função tradicional, diretiva ou instrumental" (MOCHCOVITCH, 1990 p. 53). 
Não nos parece ser interesse de parcela do empresariado na área educacional a busca por superar o debate já feito por Gramsci sobre a Escola Unitária, visto que a escola unitária para Gramsci seria fundamental para a criação das bases e dos valores de um novo humanismo. O que prevalece com o modelo defendido pelo empresariado é o reforço de uma dicotomia já histórica: uma escola da ciência para a classe burguesa e uma escola técnica e profissional para os operários.

O advento da escola unitária significa o início de novas relações entre o trabalho intelectual e o trabalho industrial não apenas na escola, mas em toda a vida social. O princípio unitário, por isso, refletir-se-á em todos os organismos de cultura, transformando-os e emprestando-lhes um novo conteúdo. (GRAMSCI, 1982, p. 125).

Mas não é só da escola que falamos aqui, nos fica claro que há dois projetos para educação em disputa. Há aquela mais humana e universal, que tem a escola como uma perspectiva emancipadora, e aquela que cresceu muito nos últimos anos, oriundo do campo privado, do setor empresarial, que defende a formação para o mercado de trabalho ou, nos dizeres de Laval (2019), a escola neoliberal.

Essas disputas poderão ser melhor compreendidas se pensamos a partir da inserção de organismo multilaterais nas políticas locais dos países de capitalismo dependente. No caso do Brasil, o Banco Mundial nos anos 1990 passou a incluir a educação em sua agenda; a educação era associada ao crescimento econômico, permitindo a estabilidade econômica nos países periféricos. O Banco mundial avaliava que a educação por si só não reduzia a pobreza, precisando de outros investimentos macroeconômicos na área sociais, o que veio a desencadear no Brasil várias outras políticas compensatórias. No nosso caso, a ideia propagada pelo banco e capitalizada por parcela de intelectuais e gestores, tem como foco a defesa de

uma educação básica com maior eficiência interna e uma efetiva redução dos custos educacionais propondo as seguintes medidas: treinamento docente, revisão de métodos pedagógicos e utilização de novos recursos materiais no ensino como a televisão e a informática, assim como a expansão do número de matriculados por sala de aula. (SEGUNDO; JIMENEZ, 2015. p.55-56).

De acordo com Leher (1998 apud SEGUNDO; JIMENEZ, 2015, p.50), o banco mundial assumiu como estratégia para sua reforma um modelo gerencial do sistema educacional, com a velha máxima que o Estado é incompetente para gerenciar os recursos, que é preciso enxugar a máquina pública e por isso reduzir o tamanho do Estado. É nesta perspectiva que o modelo gerencial proposto pelo banco mundial se encontra com o modelo empresarial, ainda como destaca Leher "a gestão eficiente do sistema educacional deve seguir os moldes empresariais, no sentido da redução dos gastos no setor. Daí a prioridade com o ensino elementar, o fluxo escolar, o currículo adequado ao mercado de trabalho e ao local.” (LEHER,1998, p.211 apud SEGUNDO; JIMENEZ, 2015, p.50)

É nesse cenário pós anos 1990, com as reformas implementadas pelo Estado Brasileiro, que as diretrizes do Banco Mundial passam a ser a implementadas. O empresariado passa assim a ter um duplo papel, por um lado um discurso de responsabilidade social de que é necessário a sociedade cuidar do social, em especial da educação, por conta do seu importante papel na formação de um novo capital humano, e que este capital humano atenda às necessidades do mercado. Por outro lado, o empresariado é 
parte constitutiva de atores que começam a desenhar e dar as diretrizes do que seria o modelo ideal de uma educação integral, onde estão postas as disputas pelo currículo, a gestão escolar, a lógica da eficiência e eficácia, típico da racionalidade do mundo empresarial.

O estado de São Paulo é um dos exemplos das mudanças que o campo privado opera na área educacional, além do conjunto de iniciativas do governo do estado de São Paulo, como centro de línguas e o Vence -programa de ampliação por meio do ensino técnico, há também o foco na formação de jovens para o mercado de trabalho. Essa política encontra suporte segundo relatório do GIFE (2015) em 63\% das fundações e institutos vinculados ao grupo.

Nosso argumento é que o empresariado, ao criar seus institutos e suas fundações, está agindo como intelectuais que são de sua classe, “Os empresários - se não todos, pelo menos uma elite deles devem possuir a capacidade de organizar a sociedade em geral, em todo o seu complexo organismo de serviços, inclusive no organismo estatal, em vista da necessidade de criar as condições mais favoráveis à expansão da própria classe" (GRAMSCI, 1982, p. 4). Com isso, o empresariado busca ser o consenso e, por meio da escola, procura construir e ser a direção moral, ética, política, criando "hábitos mentais, comportamentais que tornem os indivíduos abertos acriticamente, às exigências de novas competência" (SANFELICE, 2011, p. 6).

Assim, o empresariado, ao atuar no campo escolar, procura formar pessoas capacitadas e acríticas para que operem os interesses da classe dominante. Desse modo, falamos de uma disputa por aquilo que Gramsci chamou de aparelhos privados de hegemonia, que são instituições pertencentes à sociedade civil, ou seja, aparelhos privados estão vinculados à ideia de classe, de dominação. Mas a questão não é só se tornar classe dominante e usar dos aparelhos privados para isso, a classe dominante também que ser direção moral e intelectual.

[...] a supremacia de um grupo social se manifesta de dois modos, como "domínio" e como "direção intelectual e moral". Um grupo social domina os grupos adversários, que visa a "liquidar" ou a submeter inclusive com a força armada, e dirige os grupos afins e aliados. Um grupo social pode e, aliás, deve ser dirigente já antes de conquistar o poder governamental (esta é uma das condições principais para a própria conquista do poder); depois, quando exerce o poder e mesmo se o mantém fortemente nas mãos torna-se dominante, mas deve continuar a ser também "dirigente". (GRAMSCI, 2002 p. 62-63).

Falamos assim de hegemonia, e esta envolve ainda a totalidade da vida do sujeito, não apenas o processo político, mas a vida, as emoções, essa totalidade inicia-se em parte na vida escolar. Se uma classe quer ser hegemônica, além de envolver essa totalidade da vida do sujeito, ela tem que convencer outras classes de que essa direção interessa a todos, ou seja, a universalização dos próprios interesses, universalizar sua própria visão de mundo, a perspectiva de como se olha o mundo, e essa perspectiva de visão de mundo, em certa medida, também começa pelo sistema escolar. Daí o interesse do empresariado no campo educacional, porque ele congrega as ferramentas base de um processo pedagógico de construção de hegemonia. A Hegemonia, para Gramsci, não opera como mero domínio ideológico, como sendo uma estratégia simplesmente no nível da ideologia, no âmbito da cultura, da política. Trata-se de uma estratégia de Poder que se relaciona ao Estado, da busca pelo consenso, mas também da Força, da 
economia e da política. A hegemonia refere-se a uma racionalidade de classe que se faz história e obriga as demais classes a se pensar na história que não é delas, é a capacidade de construção do mundo próprio e autônomo, ou seja, quando uma classe consegue expandir e apresentar, alargar no sentido de abarcar, a outras classes, aqueles interesses, em um primeiro momento, restritos a uma classe. É convencer outras classes de que essa direção interessa a todos. É a universalização dos próprios interesses, universalização de sua própria visão de mundo, a perspectiva de como se olha o mundo, a racionalidade da classe.

E, mais especificamente no que se refere aos casos de RSE do banco Itaú, o que percebemos, por um lado, é a pedagogia escolar de implementar e difundir pelos estados brasileiros a lógica da educação integral. Se não é uma privatização nos termos que conhecemos, parece-nos ser uma proposição de um formato de uma linguagem mais técnica, de mercado, de um ensino voltado ao mundo do trabalho e não a um mundo mais universalista do conhecimento. Aí reside, a nosso ver, o perigo, porque passa a se implementar a ideia do sujeito privado, empreendedor de si mesmo, ou melhor, empresário de si próprio, aqui, a nosso ver, está a chave do projeto empresarial para o campo educacional.

Sobre esse modelo de projeto, Laval (2019) vai dizer que se trata da construção de uma escola neoliberal, no qual a escola vem sendo transformada em uma empresa, ao passar da regulação estatal para a regulação do mercado. O autor observa que esse processo foi iniciado, mas é algo inacabado e gera enormes contradições, sendo a maior delas o sentido dado ao aprendizado que passa dos valores culturais para os valores do mercado.

O autor, ao analisar os estados membros da união europeia e sua política para educação, vai afirmar que

Há consenso entre os estados-membros sobre a necessidade de maior envolvimento do setor privado nos sistemas de educação e/ou formação profissional e na formulação das políticas de educação e formação para atender às necessidades do mercado e das circunstâncias locais, por exemplo, sob a forma de incentivo à colaboração das empresas para o sistema de educação e formação e a à incorporação da formação continuada nos planos estratégicos das empresas. (LAVAL, 2019, p. 31).

Contudo, tal prática difundida nos países europeus, por causa da lógica do capitalismo, encontra eco no Brasil e no discurso da sociedade civil organizada, da qual os empresários fazem parte. Assim, avança a escola neoliberal (Laval, 2019), cujo valor é, acima de tudo, econômico. No caso brasileiro, essa formação econômica da escola está vinculada a sua função, no caso, vinculada à produção de um tipo de capital humano que atenda às necessidades do mercado. Como ainda destaca o autor, "colaborar com a educação não é uma obra filantrópica, e sim considerar os interesses da empresa” (LAVAL, 2019, p. 162).

Como vemos, não se trata apenas de uma ação de marketing empresarial, mas de introjetar valores e interesses do universo empresarial na esfera educacional. Isso ocorre quando olhamos para as disputas pelos currículos, que matérias devem ser privilegiadas, ou mesmo como no exemplo já exposto sobre a escola integral e o pesado lobby do Instituto Unibanco, entendido como outro braço do banco Itaú. Assim, visualizamos um projeto hegemônico sendo construído no Brasil, tendo os empresários dos mais diversos campos atuando na educação. O Itaú é apenas um dos exemplos, existe uma ação coletiva 
do empresariado nesse sentido que visa controlar o conteúdo, os métodos e as práticas educativas da classe trabalhadora, que constitui a maioria integrante do ensino público no Brasil.

O banco Itaú além de operar na área do social, por meio do Itaú Social é parte constitutiva do movimento Todos pela Educação, bem como da rede latino-americana de organizações da sociedade civil para a educação (Rede Latino-americana pela Educação - REDUCA), que é composta por outras entidades da sociedade civil que têm como foco a educação. Sabendo que a hegemonia opera no campo do simbólico, esses empresários passam a operar em redes de política (MARTINS, 2019). Assim, visualizamos que, com as mudanças impostas pelo neoliberalismo e o projeto da escola neoliberal, desenha-se no Brasil uma devastação das políticas educacionais, visto que o empresariado, ao acessar o campo escolar, passa a disputar, a desenhar uma mudança significativa na semântica e nos sentidos da própria educação, que passa a operacionalizar nos termos e nas lógicas da gestão, da eficiência e da efetividade, termos usados pelos homens de negócios. Há um processo de esvaziamento político, com um significativo enfraquecimento das lutas sociais pela educação, impondo as bases do projeto neoliberal.

\section{À guisa de conclusão}

Este trabalho buscou entender a forma como o setor privado por meio da chamada responsabilidade social empresarial, desenvolve suas ações no social. Como estudo de caso, focamos nas ações do banco Itaú, em especial a Fundação Itaú Social, visto que a ação social dos empresários, pós anos 1990 do século passado, tem como foco a sociedade civil. Para isso, usamos as pistas que o autor italiano Antônio Gramsci nos fornece sobre o processo de disputa de construção hegemônica, incorporando sua análise sobre o significado de sociedade civil, já que, para ele, a sociedade civil representa um conjunto de organismos privados, como igrejas, sindicatos, escolas etc. A construção da hegemonia, a busca de um consenso pela burguesia brasileira se dá numa relação dialética entre a esfera do que Gramsci denominou de sociedade política com a sociedade civil. Desse modo, escrevemos sobre a criação do PNBE e de outros institutos como o Instituto Ethos e o GIFE, que podem ser compreendidos, à luz de Gramsci, como aparelhos privados de hegemonia.

O empresariado adaptou não só seus discursos, mas suas práticas, voltando-se a parcerias, a projetos conjuntos e a aproximação das pautas, por exemplo, com o campo democrático participativo. Em 2015, o GIFE, em conjunto com a ABONG, participou ativamente da campanha contra a redução da maioridade penal, além de participar do Fórum Social Mundial; o Ethos ${ }^{15}$ faz campanhas entre as suas empresas afiliadas contra o trabalho escravo; todos estão envolvidos na luta pelo Marco Regulatório da Sociedade Civil, na luta por direitos (vide os eventos a favor do ECA) etc. Isto é, para uma maior inserção no campo societal, os empresários mudaram sua forma de agir, de atuar, e aproximaram-se do campo dos direitos. No presente, esse campo coberto pelo empresariado define, em certa medida, como algumas políticas públicas (como as educacionais, as culturais e, até mesmo, as relativas à criança e ao adolescente) devem ser abordadas e trabalhadas. 


\section{Referências:}

ALONSO, Jorge. La sociedad civil en óptica gramsciana. In: Sociedade civil, n.1, v.1, México, 1996.

BOBBIO, Noberto. Estado, governo, sociedade: para uma teoria geral da política. Tradução Marco Aurélio Nogueira. Rio de Janeiro: Paz e Terra, 1987.

ERNESTO, Laclau; MOUFFE, Chantal. Hegemonía y estrategia socialista: hacia una radicalización de la democracia. Buenos Aires: Fondo de Cultura Económica de Argentina.

FOLHA DE SÃO PAULO. Empresário sabe mais de gestão do que o educador, diz secretária de Goiás. Disponível em: https://m.folha.uol.com.br/educacao/2015/12/1716663-empresario-sabe-maisde-gestao-do-que-o-educador-diz-secretaria-de-goias.shtml?mobile. Acesso em 27 dez. 2015.

FREITAS, Sara da Silva. Em cena os empresários: Luta política e gestão do social. 2016. Tese (Doutorado em Sociologia) - Instituto de Filosofia, Letras e Ciências humanas. Universidade Estadual de Campinas, Campinas (SP).

GRAMSCI, Antônio. Os intelectuais e a organização da cultura. Tradução Carlos Nelson Coutinho. Rio de Janeiro: Civilização brasileira, 1982.

GRAMSCI, Antônio. Maquiavel, a política e o Estado moderno. Rio de Janeiro: Civilização Brasileira, 1976.

GRAMSCI, Antônio. Concepção dialética da História. Tradução Carlos Nelson Coutinho. Rio de Janeiro: Civilização Brasileira, 2ed., 1978.

GRAMSCI, Antônio. Cadernos do cárcere. v. 5. Rio de Janeiro: Civilização Brasileira, 2002.

GRUPPI, Luciano. O conceito de Hegemonia em Gramsci. Rio de Janeiro: Edições Graal, 2000.

LAVAL, Christian. A escola não é uma empresa: neoliberalismo em ataque ao ensino público. São Paulo: Boitempo, 2019.

LAZZARINI, Sérgio. Capitalismo de laços: os donos do Brasil e suas conexões. Rio de Janeiro: Elsevier, 2011.

MARTINS, Erika Moreira. Empresariamento da educação básica na América Latina: redes empresariais prol educação. 2019. Tese (doutorado) - Universidade Estadual de Campinas, Faculdade de Educação. Campinas - SP, 2019.

MARX, Karl. O capital, livro I. São Paulo: Boitempo, 2011.

MINELLA, Ary. Banqueiros: organização e poder político no Brasil. Rio de Janeiro: Espaço e Tempo/ ANPOCS, 1988.

MOCHCOVITCH, Luna. G. Gramsci e a escola. São Paulo: Ática, 1990.

NEVES, Lúcia M. W. A nova pedagogia da hegemonia no Brasil. Perspectiva, Florianópolis, v. 29, n. 1, 229-242, jan./jun. 2011.

OLIVEIRA, Francisco de. O capital contra a democracia. Conferência. In: Seminário: Os sentidos da democracia e da participação. São Paulo: Instituto Pólis, 2004.

OLIVEIRA, Francisco de. Os direitos do antivalor: economia política da hegemonia imperfeita. Rio de Janeiro: Vozes, 1998.

PADILHA, Paula, Z. Npc: Pesquisadora denuncia ação do Itaú para revitalizar espaços públicos. Disponível em: http://blogoosfero.cc/terrasemmales/blog/npc-pesquisadora-denuncia-acao-do-itaupara-revitalizar-espacos-publicos. Acesso em 24 abr. 2015.

PEREIRA, Franciane Corrêa. O papel social de uma instituição financeira no Rio Grande do Sul: um estudo de caso. Monografia (Aperfeiçoamento/Especialização em Controladoria). 2007, UFSM/RS. 
POLANYI, Karl. A grande transformação: as origens de nossa época. 2ed. Rio de Janeiro: Campus, 2000.

SANFELICE, José L. A nova pedagogia da hegemonia no contexto da globalização. Filosofia e educação (Online), ISSN 1984-9605 - Revista Digital do Paideia, v.2, n.2, outubro de 2010 - março de 2011.

SANTOS, Boaventura de Sousa. Pela mão de Alice: o social e o político na pós-modernidade. São Paulo: Cortez, 2005.

SEGUNDO, Maria das Dores Mendes; JIMENEZ, Susana. O papel do banco mundial na restruturação do capital: estratégias e inserção na política educacional brasileira. In: Rabelo, Jackeline et all. O movimento de educação para todos e a crítica marxista. Fortaleza: Imprensa Universitária, 2015.

URBINI, Lia Fuhrmann. Educação integral e capital financeiro: A participação do Itaú Unibanco nas políticas públicas de educação entre 2002 e 2014. Dissertação (Mestrado em Sociologia Política). Centro de Filosofia e Ciências Humanas. Universidade Federal de Santa Catarina, 2015.

\begin{abstract}
Notas
${ }^{1}$ Doutora em Sociologia pela Universidade Estadual de Campinas. Pós doutorado pelo Institute of Education (IOE) / University College London (UCL). Atualmente é pós doutoranda no Programa de pós-graduação em Ciência Política da Universidade Federal do Rio Grande do Sul. É pesquisadora do Núcleo de Estudos em Política, Estado e capitalismo na América Latina. É Integrante do projeto vinculado ao $\mathrm{CNPq} O \mathrm{O}$ Estado no pensamento social latino-americano: Perspectivas clássicas e contemporâneas - http://lattes.cnpq.br/9764495121486125. Currículo Lattes: http://lattes.cnpq.br/9764495121486125. Orcid: https://orcid.org/0000-0002-4692-4837. E-mail: sarafs77@gmail.com.

2 De modo geral podem ser encontradas diversas interpretações sobre o conceito de hegemonia. Este conceito tem suas origens na tradição marxista, em especial em Lenin. Contudo, é em Gramsci que se verifica uma noção mais elaborada e adequada para pensar as relações sociais. O autor traz à tona o debate sobre estrutura e superestrutura, ou seja, a hegemonia não operaria só no plano da economia e das organizações políticas da sociedade, mas sobre a forma de pensar, sobre as orientações ideologias e a forma de conhecer e conceber o mundo. (GRUPPI, 2000). Outras leituras surgiram a partir de Gramsci como as de Bobbio (1987), e as releituras de Ernesto Laclau e Chantal Mouffe (2004), que em Hegemonia e estratégia socialista, apontaram os limites e ambiguidades do conceito gramsciano, formulando assim, um novo conceito.

3 Dados colhidos na página do Instituto Ethos, a saber: https://www.ethos.org.br/conteudo/associados/. Acesso em 27 de maio de 2021.

4 Sobre esses dados, veja censo GIFE, disponível em: https://sinapse.gife.org.br/download/censo-gife-2009-2010.

5 O GIFE possuiu aproximadamente 130 associadas. Esse número varia a depender das entradas e saídas de novas fundações e institutos, mas, em geral, o número aproximado sempre se manteve nessa média.

6 Durante 11 meses um conjunto de jornalistas, via site Arquitetura da Gentrificação (AG), investigou um projeto de transformação urbana realizado para o Vale do Anhangabaú e áreas adjacentes do centro histórico da capital paulista, desenvolvido pelo escritório dinamarquês Gehl Architects a pedido do banco Itaú. Sobre este debate veja: https://privatizacaodarua.reporterbrasil.org.br/. Acesso em 24 abr. 2015.

7 No último relatório de 2011 de sustentabilidade do banco, o Instituto Moreira Salles não consta como vinculado à holding e dentro do campo da RSE do banco Itaú. Nossas tentativas de analisá-lo encontraram resistência justamente pelo fato de os funcionários entenderem que o instituto não conta como responsabilidade social. No entanto, por fazer parte da lista das ações do Unibanco na área de RSE, nós o consideramos.

8 Situação similar ao Instituto Moreira Salles, conforme descrevemos na nota anterior. Essa instituição também está no circuito de parceiras com organizações vinculadas à ABONG (Associação Brasileira de ONG's), conforme levantamento realizado por nós.

9 Informações disponíveis em https://www.itausocial.org.br/numeros/fundo-patrimonial-orcamento-e-despesasadministrativas/ ou ainda em: https://www.itausocial.org.br/numeros/ acesso em 27 de maio de 2021.

10 A educação integral tem como concepção de ser humano o sujeito de conhecimento, cultura, memória, de valores. E a educação integral que tem que dar conta de todas essas dimensões do ser humano, que teria que garantir o pleno desenvolvimento do ser humano. Isto difere da ideia da escola de tempo integral, defendida e propagada pelo campo empresarial. Por isso, entre as ações da fundação Itaú social, decidiu-se por optar pela prática do empresariado, no caso do Itaú, nesta área em especial, pois pensamos que aí podemos ver o real movimento empresarial no que se refere à política para escola, para os profissionais e para a educação de forma mais ampla.

11 Em uma pesquisa recente, realizada no ano de 2021 sobre esse programa, parece que ele foi atualizado e vinculado ao um novo programa, denominado redes de territórios educativos. Vide site do Itaú Social: https://www.itausocial.org.br/programas/.
\end{abstract}


12 Disponível em: http://www.icebrasil.org.br/wordpress/index.php/programas/educacao-de-qualidade/escolas-em-tempointegral/foco-de-atuacao/. Acesso em $28 \mathrm{dez} .2015$

13 Veja o site http://www.todospelaeducacao.org.br/. Acesso em 10 jan. 2016.

14 Inclui-se neste campo movimentos sociais, intelectuais, de artistas, que lutaram contra o regime militar no período autoritário no Brasil e pela abertura democrática.

15 É um instituto que tem como pauta a gestão do desenvolvimento sustentável, social ambiental no meio empresarial, podemos denominá-lo como um dos aparelhos privados de hegemonia.

Recebido em: 15 de março de 2021

Aprovado em: 14 de junho de 2021 